\title{
Predicting the spatial distribution of gambling vulnerability: An application of gravity modeling using ABS Mesh Blocks
}

\author{
Bruce Doran ${ }^{\mathrm{a}, *}$, Martin Young ${ }^{\mathrm{b}}$ \\ ${ }^{a}$ Fenner School of Environment and Society, ANU College of Medicine, Biology E Environment, Canberra, ACT 0200, Australia \\ ${ }^{\mathrm{b}}$ School for Social and Policy Research, Charles Darwin University, Australia
}

\section{Keywords:}

Gambling venues

Catchments

Gravity models

ABS Mesh Blocks

Northern Territory

Australia

\begin{abstract}
A B S T R A C T
To date, a method for the cost-effective prediction of venue catchments, and hence the spatial distribution of EGM harm, has not been available at the local level. As a first step in developing such a method, we explore the utility of a gravity modeling approach to predict the spatial distribution of venue catchments in a metropolitan region of the Northern Territory, Australia. Key inputs for the model presented include existing venue and recently released ABS Mesh Block data. We subsequently perform a combinatory analysis that integrates the predicted venue catchments with an Australian Bureau of Statistics (ABS) measure of social disadvantage to generate a gambling vulnerability surface. The advantages of this approach are that it allows visualization of catchments for effective communication, is based upon existing and current data that is available publicly through the ABS making it cost-effective, and provides a fine-grained local-level assessment of gambling vulnerability for applied policy purposes.
\end{abstract}

Crown Copyright @ 2009 Published by Elsevier Ltd. All rights reserved.

\section{Introduction}

Participation in regulated forms of gambling has increased to around $80 \%$ of the adult population of most western countries (Abbott, Volberg, \& Ronnberg, 2004; Productivity Commission, 1999; Sproston, Erens, \& Orford, 2000; Wardle et al., 2007; Welte, Barnes, Wieczorek, Tidwell, \& Parker, 2002). An activity of this magnitude is obviously highly lucrative for governments because of the large revenues accrued. In Australia, gambling taxation revenue for 2006/07 amounted to AU\$4.8 billion (Australian Bureau of Statistics, 2008a). On the flip side are the significant social costs associated with the gambling industries that were brought to the national attention of Australia in 1999 when they were quantified for the first time by the Productivity Commission (1999). In particular, the Commission measured the prevalence of problem gambling in Australia, a concept that has been defined at the national level as a behaviour '... characterised by difficulties in limiting money and/or time spent on gambling which leads to adverse consequences for the gambler, others, or for the community' (Neal, Delfabbro, \& O'Neil, 2005, p. i). The Commission estimated the prevalence of problem gambling to be $2.1 \%$ of Australia's adult population, equating to 293,000 people.

The high level of problem gambling in Australia has been largely attributed to the rapid increase in opportunities for commercial gambling, particularly electronic gaming machines (EGMs) or 'pokies' in the vernacular (devices similar to the video lottery terminals (VLTs) of other countries). EGMs have proliferated in Australia through their introduction into non-casino or 'community' venues (i.e. hotels and sporting clubs) in every jurisdiction apart from Western Australia. Noncasino EGM expenditure was AU\$10.4 billion in 2005-2006, accounting for $60 \%$ of total gambling expenditure (QOESR,

\footnotetext{
* Corresponding author. Tel.: +612 61253663; fax: +612 61250746.

E-mail address: bruce.doran@anu.edu.au (B. Doran).
} 
2006). It is this form of gambling that has consistently identified as the most problematic. In Australia, the incidence of problem gambling in jurisdictions that license EGMs in pubs and clubs is up to five times higher than the sole jurisdiction (i.e. Western Australia) that does not (South Australian Centre for Economic Studies, 2005). This pattern has also emerged overseas, where a number of studies have consistently identified EGM play as one of the most significant risk factors for problem gambling (Abbott et al., 2004; Breen \& Zimmerman, 2002; Clarke et al., 2006; Lund, 2006; Welte et al., 2002).

Regulators are charged with the responsibility of managing the social harm associated with EGM gambling while at the same time maintaining government revenues and industry profitability. To date, a method for cost-effectively predicting venue catchments, and hence the spatial distribution of EGM harm, at the local level has not been available. Consequently, regulators have tended to base licensing decisions on the social characteristics of local areas (i.e. socio-economic status) rather than on venue catchments. Recent research has demonstrated the utility of using Geographic Information Systems (GIS) to investigate EGM catchments through the geocoding of rigorous resident surveys (e.g. Doran, McMillen, \& Marshall, 2007; Marshall, McMillen, Niemeyer, \& Doran, 2004). However, such surveys are expensive, with costs typically running into the tens of thousands of dollars, meaning that regulatory bodies do not always have the resources available to map venue catchments in support of decision-making processes. As such, there is a pressing need for cost-effective approaches to EGM catchment mapping at the local level. As a first step in developing such an approach, we explore the utility of using gravity models to predict EGM venue catchments in a metropolitan region of the Northern Territory of Australia. Subsequently, we perform a combinatory analysis to integrate the predicted venue catchments with an ABS measure of social disadvantage to generate a gambling vulnerability surface. By spatially integrating venue access (or supply) and social disadvantage (or demand) at the local level the technique reported in this paper may provide a useful and cost-effective tool for researchers and policy makers alike.

\section{Literature review}

\section{Venue location and problem gambling}

Accessibility to gambling venues is of key policy concern because it has been closely connected to the incidence of problem gambling in Australia (Productivity Commission, 1999), the USA (Campbell \& Lester, 1999; Lesieur, 1992; Lester, 1994; Shaffer, Hall, \& Bilt, 1999; Volberg, 1994), Canada (Ladouceur, Jacques, Ferland, \& Giroux 1999), and Japan (Sibbitt, 1997). One of the first studies of the effect of venue location on problem gambling was conducted in the United States by Gerstein, Rachel, Volberg, Murphy, and Toce (1999). This time-series analysis from 1980 to 1997 of 1000 communities found that the availability of a casino within 50 miles (as opposed to the comparison category of 50-250 miles) was associated with a doubling in the prevalence of problem gambling. One of the most comprehensive studies to date of accessibility and problem gambling was conducted using data from a US national gambling survey in 2000 by Welte, Wieczorek, Barnes, and Tidwell (2006), Welte, Wieczorek, Barnes, Tidwell, and Hoffman (2004), Welte, Barnes, Wieczorek, Tidwell, and Hoffman (2007). Welte et al. (2004) found that a casino within 10 miles of residence almost doubled the risk of problem gambling (odd ratio of 1.9). When these results were tested for age and gender interaction in a later set of analyses, it was only problem gambling by males over 30 years that was associated with proximity to a casino (Welte et al., 2007). More detailed geographic analysis of the same dataset by Welte et al. (2006) revealed that physical availability of gambling opportunities was a significant predictor of gambling, frequent gambling, and problem gambling. Specifically, both the availability of lottery and bingo outlets increased the risk of problem gambling. Residence within three minutes of lottery outlets had double the risk of problem gambling while each bingo outlet within one mile of residence increased problem gambling risk by $20 \%$ (Welte et al. 2006).

In a similar vein, Adams, Sullivan, Horton, Menna, and Guilmette (2007) found a casino proximity effect on university students in Canada. This study examined gambling and problem gambling by Canadian university students, based on the university $(n=4)$ proximity to a casino. Students of the two universities closest to a casino displayed significantly higher rates of problem gambling than students in universities located further from a casino. It is equally evident that the introduction of new gambling venues may increase the level of harm among vulnerable groups, including existing problem gamblers. A study by Toneatto, Ferguson, and Brennan (2003) has shown that the introduction of a new casino (at Niagara Falls) impacted on a specific high-risk population (i.e. substance abusers who gambled) resulting in increased problem gambling among this group.

In the specific context of EGM venues, a recent national-scale study conducted in New Zealand of the relationship between gambling behaviour and accessibility to various gambling outlets (i.e. non-casino EGM locations, sports betting venues and casinos) found a strong proximity effect (Pearce, Mason, Hiscock, \& Day, 2008). Residents living in the closest 25\% of neighbourhoods (less than $0.7 \mathrm{kms}$ ) to non-casino EGM venues were more likely to be problem gamblers (OR 2.71) even after the logistic regression model was adjusted for age, gender, socio-economic status, and urban/rural status (Pearce et al., 2008, p. 866). Thus, it does appear that residential proximity to gambling venues is related to higher levels of problem gambling among specific social groups across a range of venue types. An important intervening factor here may be the links between accessibility and the relatively higher participation levels of economically disadvantaged populations. In other words, while proximity to gaming venues may have exposure effects, the strength of this relationship is susceptible to contextual variations. 
In 1999, the Australian Productivity Commission reported a negative and significant relationship between median weekly income (estimated as the weighted-average of median incomes of all Statistical Local Areas (SLAs) in each jurisdiction) and the number of EGMs in three out of four states studied (i.e. in Victoria, New South Wales, and South Australia but not in Queensland) (Chap. 10, p. 41). A number of subsequent Australian studies, based on regional area-level correlations, have confirmed the link between EGM density and social disadvantage (Marshall, 1999; Marshall \& Baker, 2001a, 2001b; South Australian Centre for Economic Studies, 2005). Marshall (1999) found that poorer regions in Adelaide (identified through the socio-economic status of postcode areas) were associated with increased EGM availability and expenditure. Subsequently, Marshall and Baker (2001b) examined the relationship between EGM concentration and socio-economic disadvantage across metropolitan Melbourne, the primary metropolis in Victoria. EGMs were found to be concentrated in the least advantaged local government areas (LGAs), with a corresponding lower concentration in the wealthiest LGA. These authors found a similar relationship in a subsequent study of the more established Sydney EGM market (Marshall \& Baker, 2002).

In addition, international studies have identified the same spatial relationship between gambling supply and social disadvantage. In New Zealand, Wheeler, Rigby, and Huriwai (2006) found that EGMs were disproportionately located in the most deprived areas, with fifty-three percent of machines located in the most deprived thirty-three percent of census area units. In Canada, both Wilson, Gilliland, Ross, and Derevensky (2006) and Gilliland and Ross (2005) found the spatial distribution of video lottery terminals (VLTs) in Montreal reflected local patterns of socio-economic status (SES). Therefore, at these macro-scales, the supply of EGMs appears to be related to low SES across a range of metropolitan contexts. These patterns may be explained in terms of the interactions of supply and demand in combination with some other influential factors including government policy, local political action, ethnic and cultural variations in host areas, and the historical pattern of development, all of which may act to concentrate EGMs in socially-disadvantaged areas (Marshall \& Baker, 2001b). In other words, people in poorer areas are more exposed to EGM gambling and are therefore also likely to suffer the negative consequences of gambling.

This identification of this relationship encouraged the formulation of area-based EGM capping policies for some metropolitan areas based on the level of social disadvantage, an example of which is represented by the regional caps policy of Victoria (McMillen \& Doran, 2006; Victorian Department of Justice, 2006). These policies are based on the logic that given the area-level relationship between EGM numbers and expenditure on one hand, and low SES on the other, then a restriction of the supply of machines in poorer areas or more vulnerable areas may reduce the incidence of gambling-related harm in that area. However, this logic may be challenged at the local level, where the relationship between socio-economic status and machine supply is highly variable.

Variation in the relationships between EGM supply and social disadvantage

A study by McMillen and Doran (2006) found no consistent spatial correlation between EGM expenditure and low SES at the Collector District (CD) level in three separate Victorian study areas (i.e. Maribyrnong, Central Melbourne, and greater Geelong). The relationship between EGM expenditure and disadvantage was found to vary considerably within the study areas, illustrating a local-level complexity masked by areal analyses at a broader scale. Other factors apart from SES were suggested to explain localised variation in expenditure patterns including size and type of venue, location (i.e. proximity to shopping centres, residential areas or transport corridors, the range of other facilities offered and accessibility to a wide catchment), seasonality, marketing campaigns, opening hours, and local strategies to ameliorate gambling impacts (McMillen \& Doran 2006, p. 15). This study illustrated the central role of gambling venues in mediating the relationship between supply of EGMs and their social context (i.e. SES of surrounding populations).

The primary reason for local-level variation in the relationship between EGM expenditure and social disadvantage is the fact that some people may travel to particular venues outside their local area. Consequently, even though poorer people may be playing EGMs, it is not always possible to establish a clear link which shows that EGM expenditure is derived from specific local areas of disadvantage. To explore this issue Marshall et al. (2004) measured the catchments of eight clubs in the Tuggeranong Valley, suburban Canberra (refer also Doran et al., 2007). These authors found that some catchments spanned large areas, while others were tightly defined, there was no standard distance from venue to market, and catchments had an uneven radius. Clubs with extensive catchments tended to be located near areas of community congregation (e.g. shopping centres) while clubs with small catchments were located further away, often in suburbs with lower SES (Marshall et al., 2004, p. 98). In a similar vein, Marshall's (2005) study of the Richmond-Tweed area of New South Wales found a strong relationship between distance travelled to gaming venues and expenditure on gambling, in that people who lived closer to venues tended to have higher levels of expenditure. Thus, not only does the spatial extent of venue catchments vary, so does the intensity of their impacts.

Thus, it appears that the spatial impacts of EGM gambling are heavily mediated by the location, characteristics, and social contexts of individual venues (Young \& Tyler, 2008). The resultant variability in the relationship between socio-economic status and EGM supply has important implications for policy formulation. In particular, we are unable to reliably develop area-based capping policies based on the level of social disadvantage alone (Young \& Tyler, 2008). While socio-economic status is related to EGM outcomes at a macro level, the local-level impacts are influenced by venue catchments. To develop more locally-attuned predictive models, we need a way to measure venue catchments in a cost-effective and timely fashion. 


\section{Measuring venue catchments}

The preceding review has made clear several key points. First, problem gambling is related to residential proximity to venues. Second, this effect is mediated by the SES of local communities within the catchments of venues. Third, the spatial relationship between SES, venue catchments, and problem gambling is highly variable at the local-level of analysis. Unfortunately, regulatory approaches to date have been based on an assessment of the SES of local areas alone as a surrogate for gambling vulnerability. However, such policies are flawed as they do not account for local-level variation in the relationship between venues and their catchments. Consequently, managing EGM supply of the basis of SES of local areas alone is likely to be an ineffectual approach to reducing problem gambling. To measure the spatial impact of venues at the local level we require a research tool that measures the local-level relationships between EGM venues and their surrounding populations. This necessitates an examination of the morphology, social characteristics, and levels of problem gambling associated with venue catchments for different types of venues and at different geographic scales. While we do not attempt such a complete examination in this paper, we do make a contribution towards this agenda by developing a technique to predict the spatial range and intensity of venue catchments, which we argue constitutes a first step in understanding these socio-spatial relationships (Doran, et al., 2007).

In terms of measuring venue catchments the most rigorous methods involve representative resident surveys which are subsequently geocoded and analysed using GIS-based techniques (Doran, et al., 2007; Marshall, et al., 2004). However, this technique is limited in contexts of high population mobility or where catchments may be highly attenuated (Young et al., 2006). In addition, a large-scale survey it is not always available to policy makers due to cost and research effort constraints. Therefore, we identify an important niche for a desktop-level approach to the measurement of venue catchments that enables us to use existing data, available from government agencies such as gambling regulatory bodies and the Australian Bureau of Statistics (ABS), to model and predict venue catchments. We envisage these approaches to be complementary rather than oppositional, in that effective decision-making will depend on data from a range of scales, used in an integrated fashion to identify high-risk areas for problem gambling.

\section{Study area}

The Northern Territory contains the smallest estimated resident population (ERP) of any Australian state or territory (214,975 in June 2007) yet has the third largest land area (1,346,200 km²) (Australian Bureau of Statistics, 2008a, 2008c). Half of the population live in the tropical capital city of Darwin (ERP of 72,852 in June 2007) and its satellite town Palmerston (ERP of 26,592 in June 2007) (Australian Bureau of Statistics, 2008b). The only other sizeable urban centre is the desert town of Alice Springs (ERP of 28,509 in June 2007) (Australian Bureau of Statistics, 2008b).

Both of these cities have casinos that have provided EGMs since 1981. However, EGMs were not introduced into hotels and clubs, or "community venues", until 1996, following lobbying by these venues for a greater share of the gambling market on the premise they would arrest the alleged decline in their ability to provide community services (McMillen \& Togni, 2000, p. 118). An EGM restriction policy, set at 45 machines for clubs and 10 for hotels, accompanied their introduction (Alder, 1998). Despite these capping limits on individual venues, the introduction of EGMs has steadily continued over the past decade both through venues increasing their number of machines to the maximum and through the opening of new gambling venues. The number of community venues with EGMs increased from 46 at the end of the 1996/97 financial year to 72 at the end of $2006 /$ 07. The number of actual machines in community venues has doubled from 499 in 1996/97 to 1166 in $2007 / 08$.

In this study we develop a gravity model to predict EGM venue catchments for northern Darwin (see Fig. 1 below). An examination of ABS Mesh Block data shows that the approximate resident population for this area is 45,000 people. This area is characterised by a diverse mix of suburbs with an outer ring of relatively affluent suburbs such as Nightcliff, Rapid Creek, Brinkin, Wanguri and Leanyer and an inner ring of less affluent suburbs around the airport precinct including Millner, Alawa, Wagaman, Malak and Karama. These patterns are evident in Fig. 2 below which shows the ABS Socio-economic Indexes for Areas (SEIFA) data for the measure of Advantage/Disadvantage at the Collector District (CD) level. Note that lower values represent lower a level of advantage (Trewin, 2003). This area also displays a mix of venue types and sizes, outlined in more detail in the methods section below. The study site lays approximately $15 \mathrm{kms}$ from the satellite town of Palmerston and $8 \mathrm{kms}$ from the Darwin CBD area.

\section{Methods}

Gravity models

While gravity models are frequently used to inform policy (Mátyás, 1998) and have significant application in the field of health (Guagliardo, 2004) their use in the field of gambling studies is rare (Robitaille \& Herjean, 2008). When investigating the geography of gambling opportunities at small-area scales in New Zealand, Wheeler et al. (2006) emphasized that “...no information or estimates regarding venue catchment areas are available..." However, given that gravity models have been used extensively to predict trade-area catchments (e.g. Greene \& Pick, 2006; Pick, 2005; Wang, 2006), there appears to be a strong case for their incorporation into gambling impact studies. The advantages of being able to predict the spatial extent of gambling venue catchments are that they allow the visualization of trade areas for effective communication, use existing data 


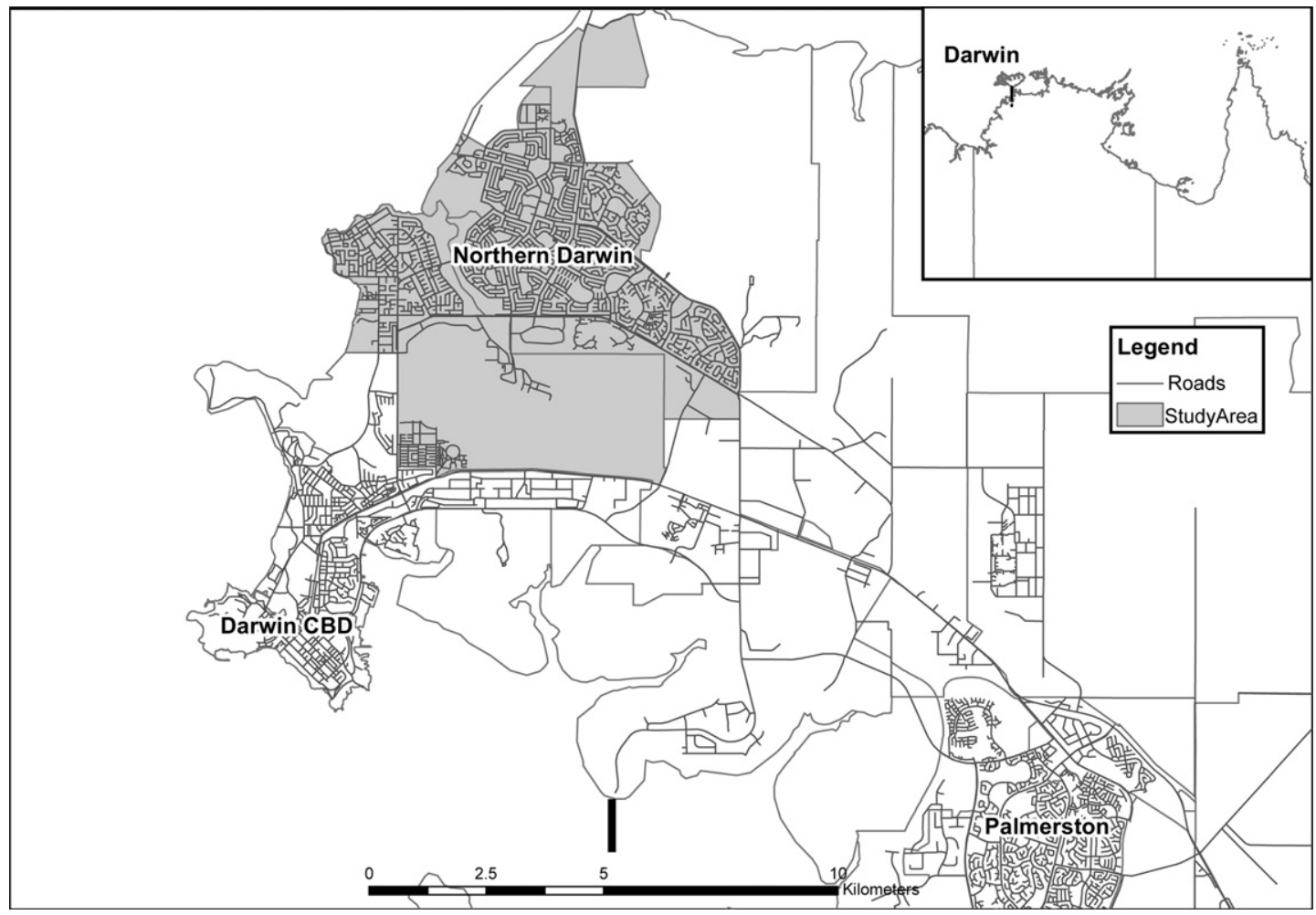

Fig. 1. The study area - northern Darwin.

publicly available through the ABS, making them cost effective, and provide a broad overview of patterns at the local level which may be used to identify key areas for policy or further research. We wish to emphasize that gravity modeling is a predictive technique based on a number of assumptions, namely that venues are homogeneous (i.e. attract the same groups); Euclidean (straight line) distance is a valid means of representing origin-destination pairs; social groups are equally mobile; catchments are constant over time; and venue attractiveness is accurately measured by the number of EGMs.

\section{ABS Mesh Blocks as building blocks for a gravity model}

In 2003, the ABS established design criteria for a new micro-level census unit, the Mesh Block (Harper, 2005). In part, the impetus to develop Mesh Blocks arose from an increased demand for users of census data to have access to small area geographic data that is more reflective of the social, physical and economic realities of the landscape (Harper, 2005). These new units are four to five times smaller than Collector Districts (CDs), contain a minimum of 20-50 total dwellings (ABS, 2007a; Harper, 2005) and are categorised according to prominent land-use type, which enables a more accurate depiction of topographic and infrastructural influences (Harper, 2005). Due to their small size, Mesh Blocks provide analysts with improved insights into the location and distribution of population clusters and the potential to conduct localised analyses such as journey to work investigations (Harper, 2005; NSW Ministry of Transport, 2008).

In February 2008 the ABS released limited statistics in the form of total population and dwelling counts for Mesh Blocks (ABS, 2008a). We use this data to form the basis of a gravity model using the INTERACTION function in Arc/INFO (version 9.2) to predict EGM venue catchments in northern Darwin. This approach uses the probabilistic Huff model which is part of many commercial GIS packages and is frequently used to perform trade-area analysis (Greene \& Pick, 2006; Pick, 2005). The generic form of the Huff model predicts the probability of a consumer located at point $i$ choosing store $j$ based on the following equation:

$$
P=S j D i j / \sum S^{\alpha} D^{\beta}
$$

where $S j$ is the size of the store and $D i j$ is the distance from $i$ to $j$ (Huff, 2003). The attractiveness of a store is represented by $\alpha$, and $\beta$ is a distance decay-function (ESRI, 2006). Gravity model applications frequently represent consumer locations, or origins, using centroids extracted from census tracts (e.g. Greene \& Pick, 2006; Pick, 2005; Wang, 2006). In our case, we have used Mesh Block centroids, weighted by the total population recorded per unit, to represent origins. The destinations for the model are the geocoded locations of the $11 \mathrm{EGM}$ venues in the study area. Destination weighting is often based on measures of 


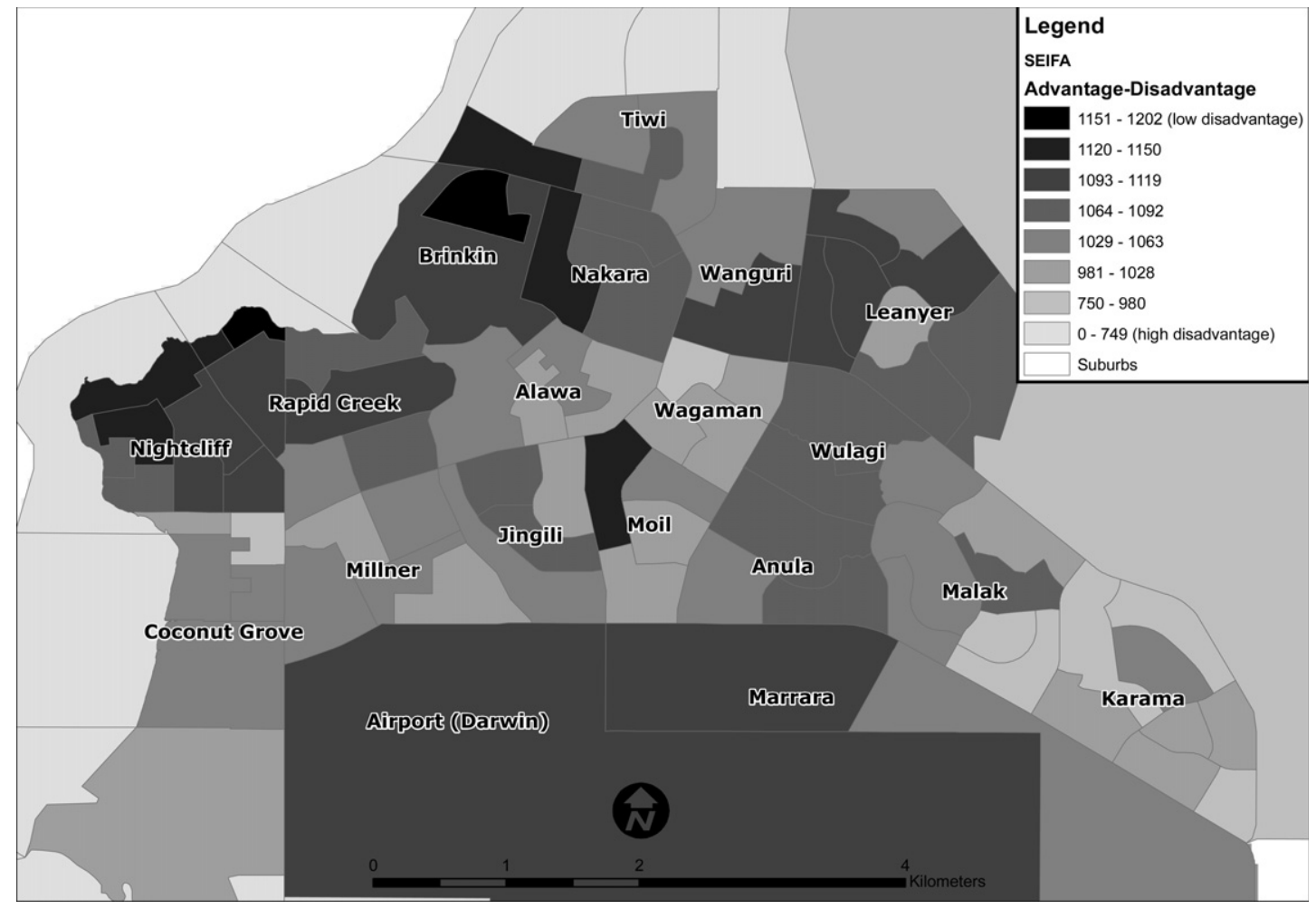

Fig. 2. The SEIFA index of advantage-disadvantage for the study area.

size such as floor space of retail areas, car parks or seating capacity (e.g. Golledge \& Stimson, 1997; Greene \& Pick, 2006). We have used the number of EGMs in each venue to weight destinations in our model. Fig. 3 shows the origins and destinations for the study area. An exponential function is recommended for the distance decay component of city-based applications (ESRI, 2006). In this case we have used an exponent of 1.5.

\section{Combinatory GIS procedure: gravity model outputs and SEIFA data}

To explore the collective impact of EGM venue catchments, a combinatory GIS procedure, represented diagrammatically in Fig. 3, was used to identify areas characterised by a high degree of overlap between socio-economic disadvantage and the outputs of the gravity model. The approach taken for the combinatory analysis was similar to that of deriving an index model

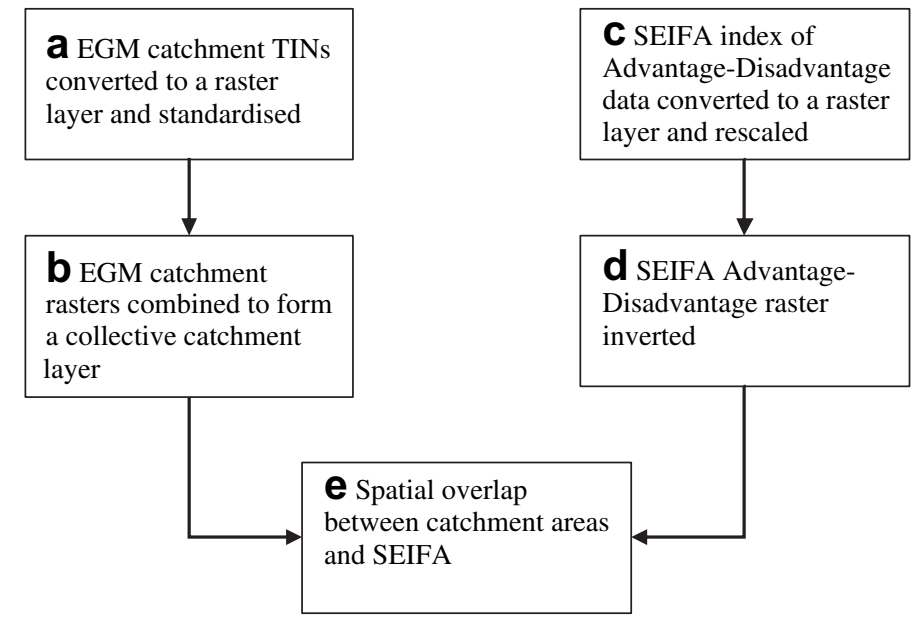

Fig. 3. Combinatory GIS procedure used to explore the collective impact of EGM venue catchments. 
where inputs are standardized before synthesis (Chang, 2008). The primary output from the INTERACTION command is a series of Triangular Irregular Networks (TINs) representing the predicted catchments of EGM venues in the study area. These TINs were then classified in ten percent intervals (ranging from a less than $10 \%$ to a greater than $90 \%$ chance of residents interacting with a venue), subsequently converted into a raster format and reclassified with values ranging from 0.0 to 1.0 (Fig. 3a). The 11 standardized rasters for each predicted venue catchment were then combined using the MAX command in ArcGIS which retains the maximum cell value of the input rasters (Fig. 3b). This generated a collective catchment output which was in turn combined with ABS SEIFA data for the index of Advantage-Disadvantage. The SEIFA data for the study region had been converted to a raster and rescaled (Fig. $3 c$ ) though dividing the by the maximum value of the layer to ensure the range was comparable with the combined catchment raster. This raster was then inverted (Fig. 3d) so that higher values represented greater levels of disadvantage. This facilitated the final step where the combined catchment raster was multiplied by the standardized and inverted SEIFA data to generate an output illustrating the degree of spatial overlap between predicted venue catchments and socio-economic disadvantage (Fig. 3e).

\section{Results}

In general, the gravity model outputs predicted two types of catchments - some which were relatively extensive and spanned much of the study area and others that had much more confined extents. Fig. 4 illustrates an example of an extensive catchment, with the core area being centered around Nakara, Wanguri, Alawa and Wagaman. Of note in this output is an obvious "caldera effect" in the core area of the catchment (labelled "A" in Fig. 4). This is caused by relatively low population counts (i.e. 4 and 17 respectively) in several Mesh Blocks classified as Commercial, compared to a mean total population value of 101.2 for all Mesh Blocks in the study area. This particular commercial area is the Casuarina Shopping precinct which comprises a mix of specialist shops, office space and entertainment facilities. Fig. 5 provides an example of a relatively confined catchment in the western part of the study area with the core area being confined largely to the densely-populated suburb of Rapid Creek. Fig. 6 shows the combined catchment raster for the study area. The primary output from the combinatory procedure, namely the gambling vulnerability surface, is shown in Fig. 7. The key patterns in this layer can be described as follows:

- A number of clear "hotspots" of vulnerability are evident in Karama; Moil-Anula; Millner-Jingili and a large "C-shaped" area running from Wagaman, through Alawa, Nakara and Wanguri.

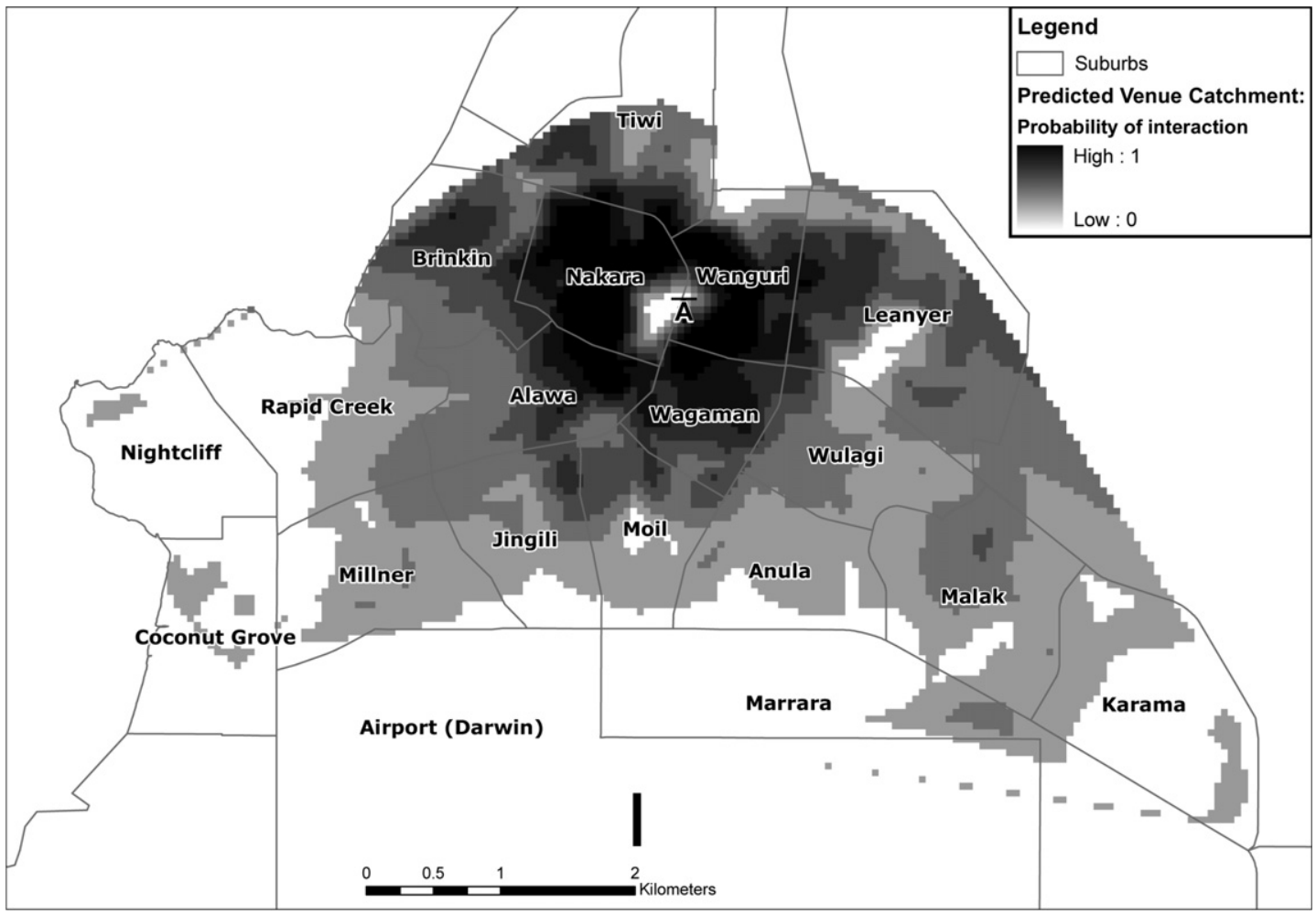

Fig. 4. An example of an extensive catchment in the study area. 


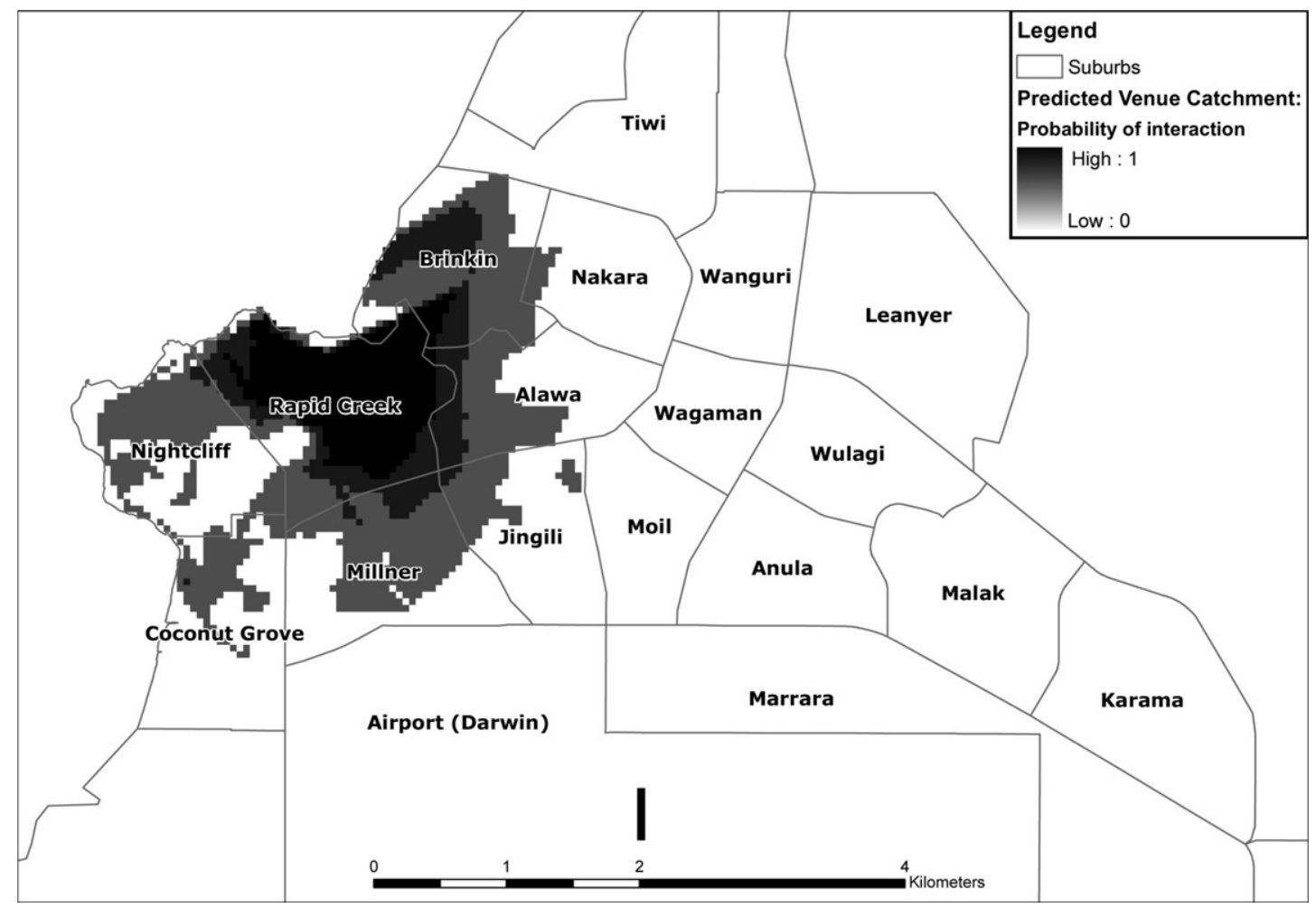

Fig. 5. An example of a confined catchment in the study area.

- Smaller, less-clearly defined, areas of vulnerability can also be seen in the northeastern part of Coconut Grove; the northern part of Rapid Creek; Leanyer and Malak.

- Channels of intermediate areas characterised by moderate-vulnerability values that appear join "hotspots" Examples of this are evident in Nakara, Tiwi, Wagaman-Moil, Jingili-Alawa and Coconut Grove-Nightcliff.

\section{Discussion}

\section{Policy implications}

The gambling vulnerability output arising from the combinatory GIS model displayed significant variation from the SEIFA distribution. If SEIFA alone was used as a basis of vulnerability prediction, we would expect an arc of vulnerability running from west to east through the suburbs located just north of the airport. However, the vulnerability surface, while partly approximating this arc, differs in some significant ways. First, the pattern of vulnerability is more intense and localised in some specific areas along this arc. These are areas including the suburbs of Karama and Moil that have both low SES and high levels of venue access. In a similar fashion, Wagaman is a relatively low SES suburb with very high venue access, and is more vulnerable than SEIFA would predict. Conversely, some areas that the SEIFA would suggest are low risk by way of the middlehigh SES are vulnerable when accessibility is introduced into the equation. Wanguri, Rapid Creek and Alawa are all suburbs that are more vulnerable than SEIFA would predict due to their high levels of accessibility to EGM venues. In summary, while the vulnerability surface does, to an extent, approximate the SEIFA arc of disadvantage, it also predicts some substantial differences in the local pattern of vulnerability. In particular, it predicts a different intensity of vulnerability for suburbs across the arc of SES disadvantage, particularly in identifying local 'hotspots' of vulnerability, but also in identifying localised hotspots to the north and west of the study area (i.e. Wagaman, Wanguri, Rapid Creek, and an area in Coconut Grove). Therefore, the gambling vulnerability index clearly indicates that a reliance on SEIFA alone is likely to be misleading at the local level of analysis.

In this sense, the vulnerability surface represents a useful tool for regulators who have, to date, been reliant on SEIFA as the primary predictor of gambling vulnerability (Victorian Department of Justice, 2006). It provides a cost-effective way to predict the spatial distribution of potential problem gambling with which to inform both EGM licensing decisions and harm-minimization strategies at the local scale. In terms of a support to decision making, the method may be used to: 


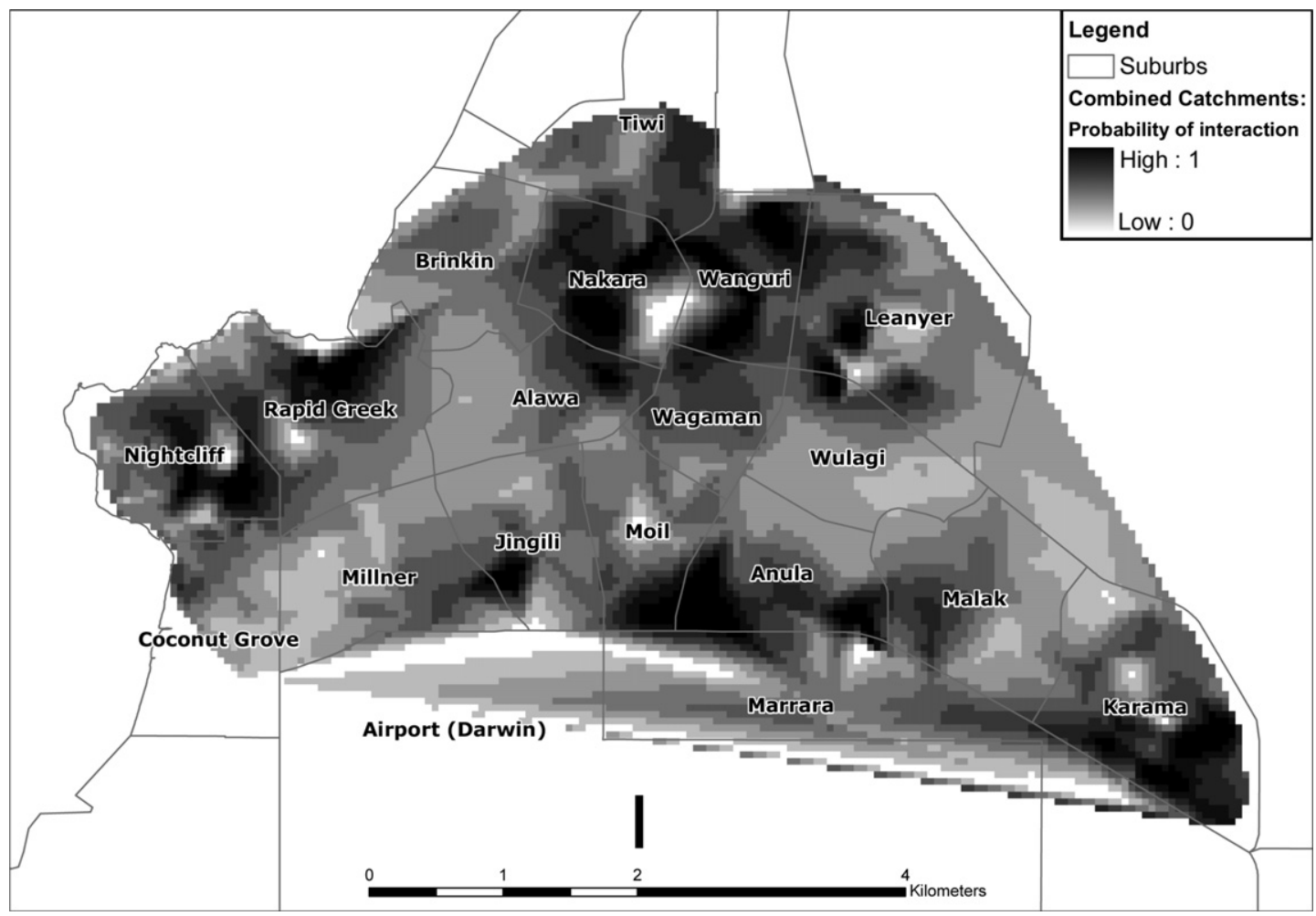

Fig. 6. Combined catchment raster.

- determine vulnerability 'hotspots' that warrant more detailed investigation;

- predict the likely social impact of the introduction of new EGM venues, an increase in number of EGMs in existing venues, or the relocation of existing machines;

- identify target areas for the redirection of EGM-generated community benefit monies;

- identify areas that may require problem gambling amelioration attempts;

- identify suitable locations for the implementation of gambling awareness and education campaigns;

- identify preferred locations for counselling and intervention services;

- assist with community planning and engagement (e.g. presentation of the vulnerability surface to locally-informed groups such as venue managers, regulators, community service organizations, and local residents); and

- predict the catchments of other types of gambling venues (e.g. betting outlets, casinos and lottery outlets)

In an operational sense, the method makes use of existing ABS and regulatory data (i.e. ABS Mesh Blocks and EGM numbers) making it highly cost-effective. One of the generic advantages of Mesh Blocks is that they allow ABS data to be published for customised areas, providing a framework for analysis that is potentially more useful and relevant than generic geographies (ABS, 2007b). The results of this paper represent a case in point. Further, Mesh Blocks are set to replace CDs in the future as the smallest unit of the ASGC (Pink, 2008). This would make it possible to develop more sophisticated means of weighting origins, other than simply using total population or dwelling counts. In addition, once the initial model parameters are established, the models may be run relatively quickly for timely assessment of venue catchments and gambling vulnerability. Moreover, the models may be run at the level of an entire jurisdiction or even nation-wide. For example, the Northern Territory is small enough in terms of the number of venues $(n=78)$ to be modelled in its entirety (an extension that is currently underway), promising a comprehensive regulatory tool not currently available in other jurisdictions. For these reasons, the approach has the potential to inform a regulatory and licensing approach that is sensitive to local-level spatial and temporal variation in gambling impacts, one that replaces the 'one-size-fits' all policies currently in place.

Limitations of the gambling vulnerability surface

One limitation of the model outputs is that non-residential Mesh Blocks (e.g. those classified as Commercial, Educational and Industrial) generate some minor distortions in the model. These Mesh Blocks typically have very low to zero population counts but nonetheless potentially contribute to EGM catchments. An example includes Casuarina Square (Darwin's main suburban shopping centre) that attracts several thousand people per day and no doubt acts a major market for the adjacent 


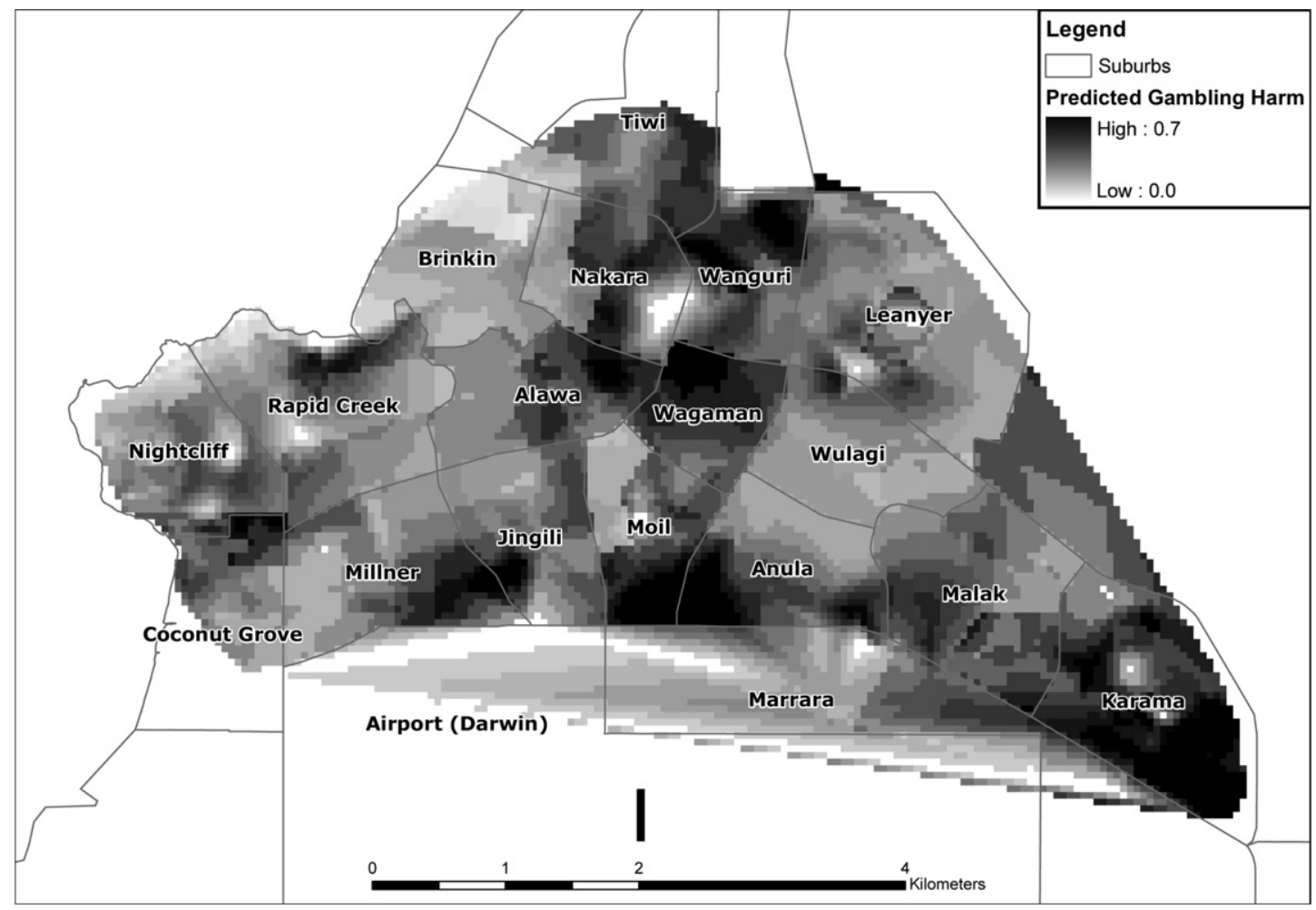

Fig. 7. Gambling vulnerability surface.

Casuarina Club. However, the gravity model of the Casuarina Club's catchment does not account for these non-residential land-use patterns. This raises the issue or origins - people may not travel to venues directly from home. Rather, they may use work as an origin or may gamble as part of a larger multi-nodal trip. These models are concerned with residential location only and do not account for daily mobility patterns (e.g. Kwan, 1999, 2000). In a similar vein, basing the index of attractiveness on raw EGM numbers alone is a fairly crude measure of destination size. Other factors, particularly the range of facilities, are likely to affect the catchment size and intensity (Marshall, 2005). Finally, the gravity model presented in this paper is based on Euclidean (i.e. straight line distance). As such, the model does not account for localised aspects of accessibility such as the potential influence of infrastructure features such as transport networks.

There are also a number of limitations associated with using the currently-available SEIFA data. The data we have used was collected in 2001 and is therefore dated particularly given the high rates of population turnover evident in the Northern Territory. Once SEIFA data from the 2006 census is made available the model will be re-run. Ideally, SEIFA would be a powerful data source at released at the level of the mesh block, but our initial inquiries have suggested this is unlikely. At a more conceptual level, because SEIFA was constructed through principle components analysis of the population in the major metropolitan regions of Australia, it may not be a particularly accurate measure of social disadvantage in some rural or remote regions such as the Northern Territory (Tyler \& Morrison, 1996).

\section{Further research}

The combinatory model we have presented is an explicitly predictive one. A logical next step in the research process is to calibrate the models through ground-truthing. In other words, further research is required to test the accuracy of the models, and make adjustments where necessary. Calibration will need to cover the following areas:

- Spatial: Comparison of predicted catchments with actual catchments (e.g. Dennis, Marsland, \& Cockett 2002) is required to determine the effects of other variables on the models, such as transport networks or venue-specific characteristics on catchment sizes. The models may then be adjusted as necessary, for example by the development of more sophisticated indicators of destination attractiveness.

- Social: Further research is needed to understand the attractiveness of venues to specific markets. Markets are socially segregated where different venue types attract different social groups. For example, pubs are more likely to attract working-class patrons and the models may be adjusted to account for this. 
- Temporal: Models could also be adjusted to account for temporal variation. Catchments are temporally segregated, particularly in highly seasonal places such as the Northern Territory. In addition, catchments are likely to vary on a daily basis, with some venues (e.g. inner city pubs and clubs) likely to attract a nocturnal market and others a more diurnal one (e.g. suburban club).

Calibration that is spatial, social, and temporal in scope would be best achieved through 'in situ' venue exit surveys. The overwhelming advantage of this method is that it is able produce data for all venue-based gamblers, many whom would not be contactable via phone-based or face-to-face residential survey (e.g. indigenous people, tourists, the military and itinerant workers).

\section{Conclusions}

The primary output of the combinatory procedure described in this paper is a gambling vulnerability index that integrates EGM venue accessibility with the SEIFA index of advantage-disadvantage. In other words, we have produced an index that combines demand (i.e. SES of areal units) with supply (the predicted catchments of venues). By combining a concern with the gambling vulnerability of low SES areas with the spatial structure of supply (measured by the locations and size of venues) this technique takes into account the local-level variations between SES and EGM supply that were described in Section 2.1.3 that have confounded spatially-accurate predictions of gambling vulnerability. The gambling vulnerability surface thus represents a useful first step in predicting the spatial distribution of EGM gambling impacts. This is a significant advancement given that regulators have, to date, been forced to rely purely on SEIFA alone as a measure of vulnerability. The information may be used to inform sensitive supply-side strategies including social impact assessment decisions, regulation of supply (i.e. number of EGMs), as well as the location of new or expanded venues.

\section{References}

Abbott, M. W., Volberg, R. A., \& Ronnberg, S. (2004). Comparing the New Zealand and Swedish national surveys of gambling and problem gambling. Journal of Gambling Studies, 20(3), 237-258.

Adams, G. R., Sullivan, A. M., Horton, K. D., Menna, R., \& Guilmette, A. M. (2007). A study of differences in Canadian university students' gambling and proximity to a casino. Journal of Gambling Issues 9-17.

Alder, O. (1998). Northern Territory Gaming Machine Industry. Report to the Department of Industries and Small Business, Northern Territory Government, Darwin.

Australian Bureau of Statistics. (2007a). Australian Bureau of Statistics - Annual report 2006-07. Cat. no. 1001.0. Canberra: ABS.

Australian Bureau of Statistics. (2007b). What's new in regional statistics. Issue 1. Cat. no. 1379.0. Canberra: ABS.

Australian Bureau of Statistics. (2008a). Taxation revenue, Australia, 2006-07. Cat. no. 5506.0. Canberra: ABS.

Australian Bureau of Statistics. (2008b). Regional population growth, Australia. Cat. no. 3218.0. Canberra: ABS.

Australian Bureau of Statistics. (2008c). Regional statistics - Northern Territory. Cat. no. 1362.7. Canberra: ABS.

Australian Bureau of Statistics. (2008d). Mesh Blocks digital boundaries, Australia - Product brief. Cat. no. 1209.0.55.002. Canberra: ABS.

Breen, R. B., \& Zimmerman, M. (2002). Rapid onset of pathological gambling in machine gamblers. Journal of Gambling Studies, 18, 31-43.

Campbell, F., \& Lester, D. (1999). The impact of gambling opportunities on compulsive gambling. Journal of Social Psychology, 139, $126-127$.

Chang, K. (2008). Introduction to geographic information systems. NY: McGraw Hill.

Clarke, D., Abbott, M., Tse, S., Townsend, S., Kingi, P., \& Manaia, W. (2006). Gender, age, ethnic and occupational associations with pathological gambling in a New Zealand urban sample. New Zealand Journal of Psychology, 35, 84-91.

Dennis, C., Marsland, D. \& Cockett, T. (2002). Central place practice: shopping centre attractiveness measures,hinterland boundaries and the UK retail hierarchy. Journal of Retailing and Consumer Services, 9, 185-199.

Doran, B., McMillen, J., \& Marshall, D. (2007). A GIS-based investigation of gaming venue catchments. Transactions in GIS, 11(4), 245-265.

Earth Systems Research Institute (ESRI). (2006). Arc/INFO online help manual. Version 9.2.

Gerstein, D., Rachel, A., Volberg, R. A., Murphy, S., \& Toce, M. (1999). Gambling impact and behavior study: Report to the national gambling impact study commission. Chicago: National Opinion and Research Centre, the University of Chicago.

Gilliland, J. A., \& Ross, N. A. (2005). Opportunities for video lottery terminal gambling in Montreal. Canadian Journal of Public Health, 96(1), 55-59.

Golledge, R. D., \& Stimson, R. J. (1997). Spatial behavior: A geographic behavior. NY: Guilford Press.

Greene, R. P., \& Pick, J. B. (2006). Exploring the urban community - A GIS approach. United States of America Prentice Hall.

Guagliardo, M. (2004). Spatial accessibility of primary care: concepts, methods and challenges. International Journal of Health Geographics, 26(3), 1-13.

Harper, P. (2005). Information paper: Draft Mesh Blocks Australia. Cat. no. 1209.0.55.001. Canberra: ABS.

Huff, D. L. (2003). Parameter estimation in the Huff model. ArcUser, October-December, 34-36.

Kwan, M. (1999). Gender, the home-work link and space-time patterns of nonemployment activities. Economic Geography, 75(4), 370-394.

Kwan, M. (2000). Interactive geovisualization of activity-travel patterns using three-dimensional geographical information systems: a methodological exploration with a large data set. Transportation Research Part C, 8, 182-203.

Ladouceur, R., Jacques, C., Ferland, F., \& Giroux, I. (1999). Prevalence of problem gambling: a replication study 7 years later. Canadian Journal of Psychiatry, 44 , 802-804.

Lesieur, H. R. (1992). Compulsive gambling. Society, 29, 43-50.

Lester, D. (1994). Access to gambling opportunities and compulsive gambling. International Journal of the Addictions, 29, 1611-1616.

Lund, I. (2006). Gambling and problem gambling in Norway: what part does the gambling machine play? Addiction Research E Theory, $14,475-491$.

McMillen, J., \& Doran, B. (2006). Problem gambling and gaming machine density: socio-spatial analysis of three Victorian localities. International Gambling Studies, 6(1), 5-29.

McMillen, J., \& Togni, S. (2000). Study of gambling in the northern territory 1996-97. Australian Institute of Gambling Research, University of Western Sydney.

Marshall, D. C. (1999). Adelaide's pokie geography: distribution of, and expenditure on, electronic gaming machines in Adelaide. South Australian Geographical Journal, 98, 19-29.

Marshall, D. C. (2005). The gambling environment and gambler behaviour: evidence from Richmond-Tweed, Australia. International Gambling Studies, 5(1), 63-83.

Marshall, D. C., \& Baker, R. G. V. (2001a). Clubs, spades, diamonds and disadvantage: the geography of electronic gaming machines in Melbourne. Australian Geographical Studies, 39(1), 17-33. 
Marshall, D. C., \& Baker, R. G. V. (2001b). Unfair odds? Factors influencing the distribution of electronic gaming machines in Melbourne. Urban Policy and Research, 19(1), 77-92.

Marshall, D. C., \& Baker, R. G. V. (2002). The evolving market structures of gambling: case studies modelling the socioeconomic assignment of gaming machines in Melbourne and Sydney, Australia. Journal of Gambling Studies, 18(3), 273.

Marshall, D. C., McMillen, J., Niemeyer, S., \& Doran, B. (2004). Gaming machine accessibility and use in suburban Canberra: A detailed analysis of the Tuggeranong valley. Canberrra: The Centre for Gambling Research, Australian National University.

Mátyás, L. (1998). The gravity model: some econometric considerations. The World Economy, 21(3), $397-401$.

Ministry of Transport, N.S.W. (2008). Infosheet: 2006 Journey to work tables. NSW Ministry of Transport.

Neal, P., Delfabbro, P. H., \& O’Neil, M. (2005). Problem gambling and harm: Towards a national definition. Melbourne: Report prepared for the National Gambling Research Program Working Party.

Pearce, J., Mason, K., Hiscock, R., \& Day, P. (2008). A national study of neighborhood access to gambling opportunities and individual gambling behaviour. Journal of Epidemiology and Community Health, 62, 862-868.

Pick, J. B. (2005). Geographic information systems in business. Hershey: Idea Group Publishing.

Pink, B. (2008). 2008 Yearbook Australia. Cat. no. 1301.0. Canberra: ABS.

Productivity Commission. (1999). Australia's gambling industries: Inquiry Report No.10. Melbourne: Productivity Commission.

QOESR. (2006). Australian gambling statistics 1978-79 to 2004-05. Brisbane: Queensland Government Office of Economic and Statistical Research.

Robitaille, E., \& Herjean, P. (2008). An analysis of the accessibility of video lottery terminals: the case of Montreal. International Journal of Health Geographics, $7(2)$. [on line publication].

Shaffer, H. J., Hall, M. N., \& Bilt, J. V. (1999). Estimating the prevalence of disordered gambling behavior in the United States and Canada: a research synthesis. American Journal of Public Health, 89, 1369-1375.

Sibbitt, E. (1997). Regulating gambling in the shadow of the law: form and substance in the regulation of Japan's pachinko industry. Harvard International law Journal, 38, 568-586.

South Australian Centre for Economic Studies. (2005). Community impacts of electronic gaming machine gambling (Part A). Melbourne: Department of Justice, State of Victoria.

Sproston, K., Erens, B., \& Orford, J. (2000). Gambling behaviour in Britain: Results form the British gambling prevalence survey. London: National Centre for Social Research.

Toneatto, T., Ferguson, D., \& Brennan, J. (2003). Effect of a new casino on problem gambling in treatment-seeking substance abusers. Canadian Journal of Psychiatry, 48, 40.

Trewin, D. (2003). Socio-economic indexes for areas Australia - Information paper. Canberra: ABS.

Tyler, W., \& Morrison, P. (1996). Dimensions of disadvantage: developing small area indicators for remote Australia. Australian Journal of Social Research, 2(1), 59-80.

Victorian Department of Justice. (2006). Taking action on problem gambling: A strategy for combating problem gambling in Victoria. Melbourne: Office of Gaming and Racing, State of Victoria.

Volberg, R. A. (1994). The prevalence and demographics of pathological gamblers: implications for public health. American Journal of Public Health, 84, 237-241.

Wang, F. (2006). Quantitative methods and applications in GIS. Boca Raton: Taylor and Francis.

Wardle, H., Sproston, K., Orford, J., Erens, B., Griffiths, M., Constantine, R., et al. (2007). British gambling prevalence survey 2007. London: National Centre for Social Research.

Welte, J. W., Barnes, G. M., Wieczorek, W. F., Tidwell, M.-C. O., \& Parker, J. C. (2002). Gambling participation in the U.S: results from a national survey. Journal of Gambling Studies, 18(4), 313-337.

Welte, J. W., Wieczorek, W. F., Barnes, G. M., \& Tidwell, M. O. (2006). Multiple risk factors for frequent and problem gambling: individual, social, and ecological. Journal of Applied Social Psychoogy, 36, 1548-1568.

Welte, J. W., Wieczorek, W. F., Barnes, G. M., Tidwell, M. O., \& Hoffman, J. H. (2004). The relationship of ecological and geographic factors to gambling behavior and pathology. Journal of Gambling Studies, 20, 405-423.

Welte, J. W., Barnes, G. M., Wieczorek, W. F., Tidwell, M. O., \& Hoffman, J. H. (2007). Type of gambling and availability of risk factors for problem gambling: a tobit regression analysis by age and gender. International Gambling Studies, 7, 183-198.

Wheeler, B. W., Rigby, J. E., \& Huriwai, T. (2006). Pokies and poverty: problem gambling risk factor geography in New Zealand. Health E' Place, 12(1), 86-96.

Wilson, D., Gilliland, J., Ross, N., Derevensky, J., \& R G. (2006). Video lottery terminal access and gambling among high school students in Montreal. Canadian Journal of Public Health, 97(3), 202-206.

Young, M., Abu-Duhou, I., Barnes, T., Creed, E., Morris, M., Stevens, M., et al. (2006). Northern territory gambling prevalence survey 2005. Darwin: School for Social and Policy Research, Charles Darwin University.

Young, M., \& Tyler, W. (2008). Mediating markets: gambling venues, communities and social harm. Gambling Research, 20(1), 50-65. 